\title{
Nevo palpebral dividido - "kissing nevus". Relato clínico- patológico e tratamento cirúrgico de três casos
}

\author{
Divided nevus of the eyelid - kissing nevus. Clinicopathological report and surgical \\ treatment of three cases
}

Eduardo Ferrari Marback ${ }^{1}$

Lívia Maria Bittencourt Nossa ${ }^{2}$

Carlos Freitas Maciel ${ }^{3}$

Roberto Lorens Marback ${ }^{4}$

\section{RESUMO}

Objetivo: Relatar aspectos clínico-patológicos e tratamento cirúrgico em três casos de nevo palpebral dividido - "kissing nevus". Métodos: Revisão dos prontuários de três pacientes portadores de nevo palpebral dividido. Análise dos aspectos clínico-patológicos, das técnicas cirúrgicas e resultados do tratamento. Resultados: A cura das lesões com bom resultado estético e funcional foi conseguida em todos os casos. Conclusões: A exérese do nevo palpebral dividido, em mais de um tempo cirúrgico utilizando deslizamento de retalhos cutâneos palpebrais e, em um caso, transplante de pele da pálpebra superior contralateral foi curativa nos três casos estudados.

Descritores: Nevo pigmentado/cirurgia; Pálpebra/cirurgia; Transplante de pele/métodos; Procedimentos cirúrgicos reconstrutivos; Relato de caso

\section{INTRODUÇÃOO}

O nevo dividido palpebral "kissing nevus" é defeito embrionário raro, com cerca de trinta casos relatados na literatura oftalmológica ${ }^{(1)}$. A condição geralmente causa sérios problemas estéticos. O estudo clínico-patológico de três casos de nevo palpebral dividido e o tratamento cirúrgico empregado motivou o presente relato.

\section{RELATO DE CASOS}

\section{Caso 1}

Mulher de 41 anos, negra, atendida no Hospital Universitário Professor Edgard Santos, apresentando lesão melanótica congênita que comprometia a porção central de ambas as pálpebras à esquerda, com envolvimento das bordas palpebrais na área do tumor (Figura 1).

Durante a primeira cirurgia, foi realizada exérese do tumor da pálpebra inferior e desbaste da lesão da borda palpebral com rotação de retalho de pele palpebral para recobrimento do defeito. Quatro meses após, procedeuse a excisão da metade inferior do tumor da pálpebra superior e deslizamento de retalho cutâneo da região temporal. Foi igualmente realizado desbaste da porção situada na borda palpebral. No terceiro tempo cirúrgico, realizado após outros quatro meses foi retirada mais uma parte da lesão da pálpebra superior com enxerto de pele total da pálpebra superior contralateral. Após sete meses, na quarta e última cirurgia, foi efetuada a exérese do remanes- 


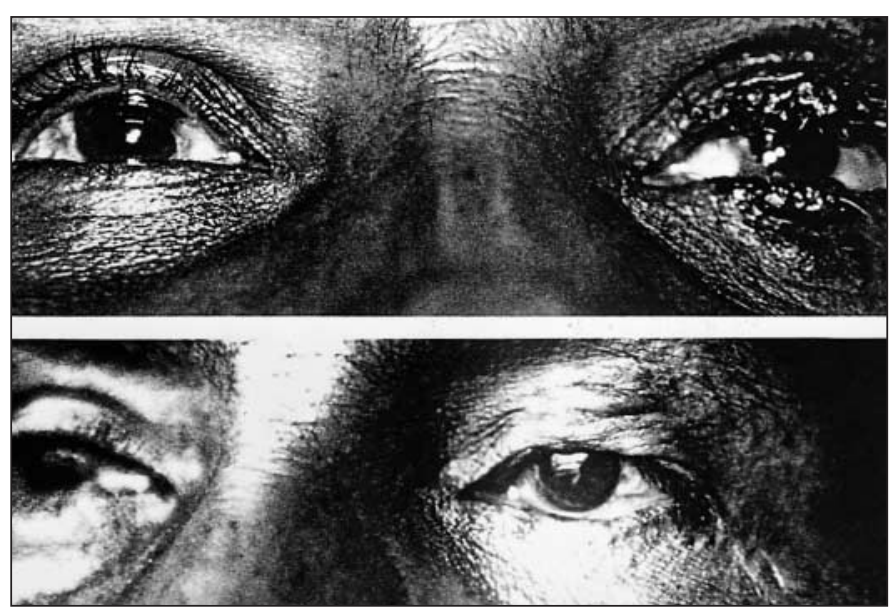

Figura 1 - Caso 1: Fotografia clínica. Lesão melanótica comprometendo a porção central de ambas pálpebras esquerdas, incluindo bordas palpebrais (acima). Resultado estético satisfatório após o tratamento cirúrgico (abaixo)

cente da lesão da pálpebra superior com rotação de retalho de pele lateralmente situada, obtendo-se a cura, com ausência de cílios nas áreas previamente afetadas (Figura 1). Todos os procedimentos foram realizados sob anestesia local.

O estudo histopatológico do material obtido durante as cirurgias revelou o diagnóstico de nevo intradérmico.

\section{Caso 2}

Paciente do sexo feminino, 14 anos, mulata. Ao ser atendida no Hospital São Rafael, Salvador - Bahia, exibia lesão melanótica, desde o nascimento, comprometendo pele e borda do terço médio de ambas as pálpebras à direita (Figura 2).

Durante o primeiro ato cirúrgico foi submetida, sob anestesia local, à exérese da lesão da pálpebra inferior com deslizamento de retalho da pele de ambos os lados e desbaste da borda palpebral correspondente. Três meses após, a mesma técnica cirúrgica foi empregada para o tratamento da lesão da pálpebra superior direita.

O estudo histopatológico da lesão existente na pálpebra inferior revelou o diagnóstico de nevo composto, enquanto que a lesão da pálpebra superior foi diagnosticada como nevo intradérmico.

O resultado estético e funcional obtido foi bastante satisfatório, restando apenas ausência de cílios nas áreas operadas (Figura 2).

\section{Caso 3}

Paciente do sexo feminino, 19 anos, mulata, procurou o Hospital Universitário Professor Edgard Santos apresentando desde o nascimento, lesão melânica ocupando o terço medial e bordas de ambas as pálpebras à direita (Figura 3).

Submetida à primeira cirurgia sob anestesia local, não foi possível identificar o ponto lacrimal superior, situado em plena lesão. Realizado desbaste da lesão na borda palpebral e exérese da mesma, seguida de rotação de retalho de pele situada superiormente.

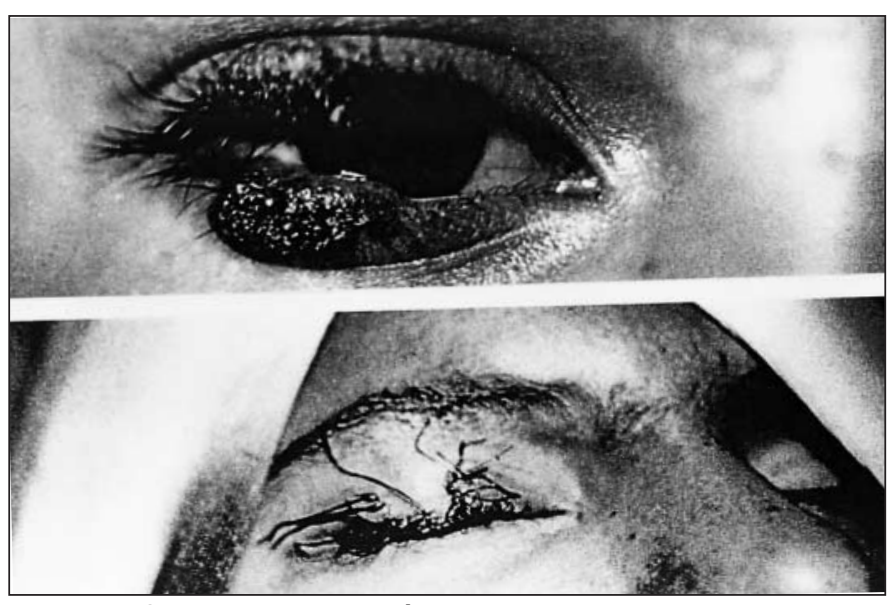

Figura 2 - Caso 2: Fotografia clínica. Nevo dividido envolvendo a pele e borda das pálpebras à direita (acima). Após a segunda cirurgia ambas pálbebras estão livres do tumor (abaixo)

Após quatro meses, também sob anestesia local, foi realizado na pálpebra inferior o mesmo tipo de cirurgia, sendo possível identificar e preservar pérvio o ponto lacrimal inferior.

A histopatologia indicou o diagnóstico de nevo intradérmico em ambas as lesões.

Houve perda de cílios nas áreas previamente ocupadas pelas mesmas (Figura 3).

\section{DISCUSSÃO}

O nevo dividido palpebral representa lesão melanocítica benigna, com origem na célula névica. Tais nevos nevocelulares são histologicamente classificados em: juncionais, compostos e intradérmicos ${ }^{(2)}$. Em estudos histopatológicos prévios, o nevo dividido palpebral foi descrito como do tipo composto $^{(1,3)}$. Nos casos em discussão, o estudo histopatológico revelou o diagnóstico de nevo intradérmico em ambas as

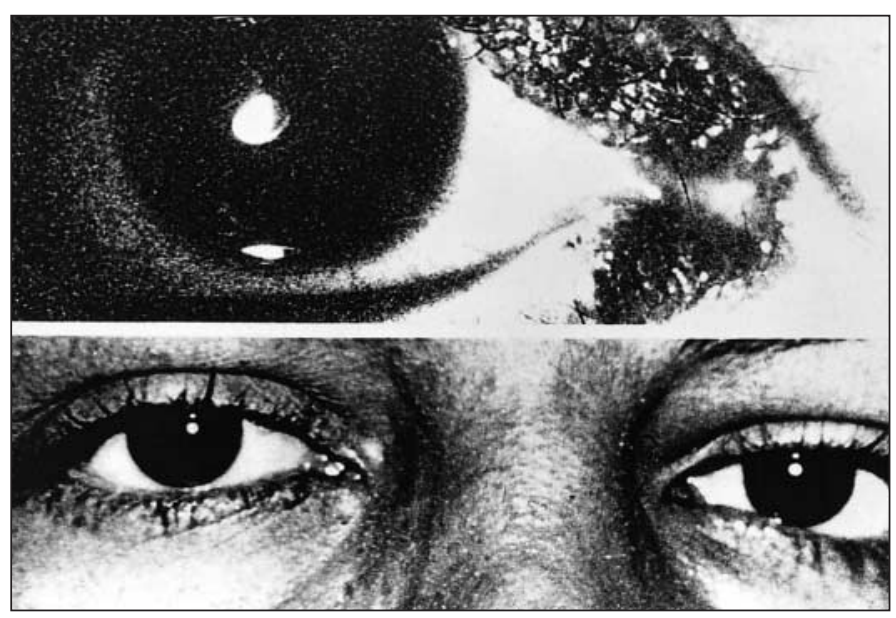

Figura 3 - Caso 3: Fotografia clínica. Nevo dividido localizado no terço medial de ambas pálpebras à direita. Observa-se o comprometimento das bordas palpebrais (acima). Resultado pós-operatório (abaixo) 
lesões dos casos 1, 3. O caso 2 teve diagnóstico de nevo intradérmico na lesão da pálpebra superior, e nevo composto na lesão de pálpebra inferior.

Apesar de ter origem em células névicas da epiderme, tais células apresentam a potencialidade de mergulhar na derme; daí, alguns nevos que aparentam ser puramente intradérmicos em determinadas áreas serem caracterizados como nevos compostos em outras áreas, como aconteceu com o caso número $2^{(4)}$. Acredita-se atualmente, que os nevos intradérmicos, compostos e juncionais resultem do seqüestro e subseqüente proliferação de células pluripotenciais da crista neural durante sua migração para a epiderme.

O nevo dividido palpebral tem a sua origem a partir da oitava semana de vida embrionária, quando ocorre a fusão das bordas palpebrais contendo células névicas. As dobras palpebrais permanecem em estado de fusão até o fim do quinto mês de vida intra-uterina e a separação resulta em lesão com aspecto espelhado, comprometendo margem e pele palpebral de áreas adjacentes de ambas as pálpebras, daí a denominação de nevo dividido(2).

O nevo dividido palpebral é condição relativamente rara. A maior série estudada foi de apenas nove $\operatorname{casos}^{(1)}$. A revisão realizada no referido estudo conseguiu reunir o total de apenas vinte e quatro casos publicados.

Quanto ao seu tratamento, devemos levar em conta que muitos pacientes o solicitam face ao aspecto estético. Desde que não existem casos descritos de transformação maligna de nevo palpebral dividido(5), a ressecção cirúrgica ampla ou radical não se faz necessária. De fato, Papadopoulos ${ }^{(1)}$ descreveu o tratamento cirúrgico de um grande nevo dividido palpebral com excelente resultado, utilizando retalho da própria pele palpebral e enxerto de pele total da pálpebra contralateral. Nos casos ora apresentados conseguimos igualmente obter bons resultados estéticos e funcionais com exérese das lesões, desbaste da lesão ao nível das bordas palpebrais, retalho por deslizamento da pele adjacente e, em apenas um caso, utilização de enxerto de pele total da pálpebra contralateral. Este último, utilizado face à grande extensão da lesão melanocítica.

O tratamento empregado resultou em ausência pós-operatória de cílios nas áreas tratadas. Entretanto tal sequiela não representou insatisfação para aos pacientes, quando comparada com o desagradável aspecto cosmético anterior.

\section{ABSTRACT}

Purpose: To describe the clinical and pathological aspects, surgical treatment and results of three cases of divided nevus -"kissing nevus"- of the eyelid. Methods: Review of the clinicopathological data and surgical techniques used to treat these patients. Results: Cure of the lesions with good esthetic and functional results were obtained in all cases. Conclusions: Surgical excision of the divided nevus of the eyelid in more than one surgical session using flaps from the adjacent skin, and in one case, a free skin graft from the contralateral superior lid, was curative in the studied three cases.

Keywords: Pigmented nevus/surgery; Skin transplantation/ methods; Eyelids/surgery; Reconstructive surgical procedures; Case report

\section{REFERÊNCIAS}

1. Papadopoulos O. Divided nevus of the eyelid. Plast Reconstr Surg 1991;88:331-3.

2. Font RL. Eyelid and lacrimal system. In: Spencer. W.H. Ophthalmic pathology. An atlas and textbook. 4th. ed. Philadelphia: W.B. Saunders; 1996. p. 2218-407.

3. John SM, Hamm H, Happle R. Der geteilte navus ein embryologisches experiment der natur. Hautarzt 1990;41:696-8.

4. Ehlers N. Divided nevus. Acta Ophthalmol (Copenh). 1969;47:1004-11.

5. Patrinely JR. Surgical management of divided nevus of the eyelid [correspondence]. Plast Reconstr Surg 1992;89:1175-6.

\title{
LIV JORNADA DO CENTRO BRASILEIRO DE ESTRABISMO
}

\section{DE MAIO DE 2002}

\section{HOTEL FLÓRIDA - RIO DE JANEIRO}

\section{Informações:}

\author{
Tel.: (1 1) 3266-4000 (c/ lza) ou \\ (21) 2610-1452 (c/ Dr. Renato Curi) \\ Fax: (11) 3171-0953 \\ e-mail: iza.cbo@cbo-sp.com.br
}

